\title{
Condições de trabalho docente na universidade pública brasileira: um mapeamento de estudos
}

\author{
Ana Carolina Pessoa Brandão* \\ Alvanize Valente Fernandes Ferenc ${ }^{* *}$ \\ Rita de Cássia Alcântara Braúna ${ }^{* * *}$
}

\section{Resumo}

Este trabalho consiste em uma sistematização de estudos sobre as condições de trabalho docente na universidade pública brasileira, publicados no período de 2006-2010, em três fontes: Reuniões Anuais da ANPEd, Banco de Teses e Dissertações da Capes e Revista Universidade e Sociedade. Buscou-se mapear e analisar as publicações oriundas dessas fontes. O trabalho iniciou-se com uma pesquisa bibliográfica sobre o trabalho docente na universidade pública brasileira; em seguida procedeu-se a um levantamento das produções sobre o referido tema nas três fontes mencionadas. Dentre as evidências dos artigos mapeados, pode-se destacar: o estudo do tema em questão ainda aparece de forma incipiente nas reuniões anuais da ANPEd e no Banco de Teses e Dissertações da Capes. Já na Revista Universidade e Sociedade ele é significativamente contemplado, o que pode ser justificado pelo fato de esta revista ter como foco de problematização questões afeitas ao ensino superior. Diante da revisão feita, entende-se que os estudos sobre as condições de trabalho docente na universidade pública ainda constituem uma lacuna e precisam de maior investimento, sobretudo na conjuntura de expansão das instituições públicas de ensino superior no contexto do Reuni.

Palavras-chave: Trabalho docente. Condições de trabalho. Universidade pública.

Recebido: 19/04/2015 - Aprovado: 31/08/2015

http://dx.doi.org/10.5335/rep.v22i2.5561

Mestre em Educação pela Universidade Federal de Viçosa. Supervisora Pedagógica da Rede Estadual de Ensino-Viçosa/MG. E-mail: carolinapbrandao@hotmail.com

** Doutora em Educação pela Universidade Federal de São Carlos. Professora Adjunta do Departamento de Educação da Universidade Federal de Viçosa, na área de Fundamentos de Educação. E-mail: avalenteferenc@gmail.com

*** Doutora em Educação pela Universidade Federal de Minas Gerais. Professora Associada do Departamento de Educação e do Programa de Pós-Graduação em Educação da Universidade Federal de Viçosa/MG, na área de Metodologia de Ensino e Didática. E-mail: rbrauna@ufv.br 


\section{Introdução}

Pesquisadores como Oliveira et al. (2002), embora enfatizem haver, atualmente, o ressurgimento da pesquisa sobre trabalho docente, indicam que esses estudos nem sempre abordam as condições nas quais esse trabalho ocorre. A maioria das pesquisas sobre trabalho docente na década de 1990 caracterizou-se por produções mais centradas nas relações de mercado de trabalho em detrimento daquelas inerentes ao processo de trabalho. Os estudos enfatizam a problemática da qualificação, das competências e das relações de emprego como tema central. Os autores evidenciam que a maior parte dos estudos sobre o tema na atualidade analisa a representação do trabalho docente. São estudos que constroem suas análises a partir do que os docentes relatam sobre seu trabalho.

Procurando aprofundar a compreensão da temática "condições de trabalho docente na universidade pública brasileira" foi desenvolvida uma revisão de estudos sobre o trabalho docente na universidade pública brasileira; em seguida foi desenvolvido um levantamento das produções sobre o referido tema em três fontes: Reuniões Anuais da Associação Nacional de Pós-Graduação e Pesquisa em Educação (ANPEd) [2006-2010], Banco de Teses e Dissertações da Coordenação de Aperfeiçoamento de Pessoal de Nível Superior (Capes) [2006-2010] e Revista Universidade e Sociedade [2006-2011]. Buscou-se mapear e analisar as publicações oriundas dessas fontes, o que pode ser configurado como estudo do tipo "estado da arte" ou "estado do conhecimento" (ANDRÉ et al, 1999). Incipiente no Brasil, atualmente esse tipo de estudo tende a contribuir para a apreensão de um dado campo do conhecimento, analisando as produções, lacunas, possibilidades e desafios existentes em tal campo investigativo (ROMANOWSKI; ENS, 2006).

Nesse sentido, o artigo se encontra organizado em duas partes: em uma primeira na qual problematizamos o trabalho docente na universidade pública, evidenciando um contexto marcado por políticas públicas que, conectadas à globalização econômica, dão novos contornos às políticas sociais; e em uma segunda parte onde se encontra a sistematização de estudos das três fontes citadas e se apontam as lacunas dos estudos sobre o tema e a demanda por problematizá-lo, sobretudo no contexto atual de expansão da universidade orientado pelo Programa de Apoio a Planos de Reestruturação e Expansão das Universidades Federais (Reuni), que foi instituído pelo Decreto $\mathrm{n}^{\mathrm{0}}$ 6.096, de 24 de abril de 2007, e faz parte do Plano de Desenvolvimento da Educação (PDE), lançado pelo governo federal. O PDE, por sua vez está articulado a um conjunto de ações presentes no Programa de Aceleração do Crescimento (PAC 2007-2010), lançado em janeiro de 2007.

O Reuni apresenta como objetivo: 
[...] criar condições para a ampliação do acesso e permanência na educação superior, no nível de graduação, para o aumento da qualidade dos cursos e pelo melhor aproveitamento da estrutura física e de recursos humanos existentes nas universidades federais, respeitadas as características particulares de cada instituição e estimulada a diversidade do sistema de ensino superior (BRASIL. Decreto nํㅜ 6.096, de 24 de abr. 2007).

\section{0 trabalho docente na universidade pública brasileira: breve contextualização}

Os estudos realizados permitem compreender que o trabalho docente não pode ser pensado isoladamente, fora das transformações que estão ocorrendo também em outros setores socioeconômicos. No atual estágio do capitalismo, têm sido executadas políticas públicas que, vinculadas à globalização econômica, reconfiguram as políticas sociais.

As reformas educacionais iniciadas nas últimas décadas no Brasil têm trazido mudanças expressivas para os trabalhadores docentes. A educação assume um novo valor e uma necessidade de adaptar-se às condições do mercado por meio de estratégias que atendam aos interesses de manutenção das condições de acumulação capitalista.

Percebemos, assim, que a esfera educacional é amplamente afetada pelas alterações provocadas pelas reformas. Segundo Santos (2004, p. 1146), "este processo faz parte do ajuste estrutural, em que a criação do Estado Mínimo exige reformas que repassem para o setor privado encargos e compromissos até então assumidos pelo setor público". Nessa situação, o setor educacional fica à mercê de critérios de eficiência e eficácia, em consonância com interesses do mercado, que alicerçam mudanças de várias ordens no sistema de ensino.

Essas mudanças tiveram uma clara incidência na vida e no trabalho dos professores universitários vinculados à universidade pública brasileira. As demandas para esses variam de acordo com as grandes mudanças estruturais e funcionais que a universidade sofreu. Nesse contexto, Maués (2008, p. 21) afirma:

[...] a produção do conhecimento, finalidade maior das Universidades, foi condicionada à lógica do mercado e os professores, como protagonistas dessas ações, têm sofrido pressões imensuráveis para que sejam produtivos e eficientes o que vem alterando significativamente o trabalho docente.

Nesse sentido, o que se pode analisar a partir dessas questões é que cada vez mais o trabalho do professor, das universidades públicas especialmente, tem se expandido para além do campo pedagógico, e esse profissional, por sua vez, vem vivenciando um processo de intensificação e precarização de seu trabalho, com consequente enfraquecimento de sua autonomia, aqui entendida como condição de participar da concepção e organização do seu trabalho. 
Reforçando essa ideia, Oliveira (2004, p. 1127), afirma que "as mudanças trazidas pelas reformas educacionais mais recentes têm resultado em intensificação do trabalho docente, ampliação do seu raio de ação e, consequentemente, em maiores desgastes e insatisfação por parte desses trabalhadores".

A intensificação do trabalho docente é entendida como a ampliação das responsabilidades e atribuições no cotidiano dos professores, ou seja, maior número de exigências para serem cumpridas em menos tempo. Desse modo, ao mudar as formas institucionais do trabalho docente, esse, consequentemente, tem a sua rotina alterada.

Autores como Bosi (2007) e Santos (2004) alertam para o impacto ideológico causado por uma ressocialização dos docentes com base em um padrão produtivista, um tipo de "cultura do desempenho", sob o qual o trabalho docente é permanentemente pontuado, trazido em números e intensificado por diversos e complexos sistemas de avaliações institucionais, que a cada ano aumentam as exigências de produção acadêmica, e dessa forma redefinem as formas de trabalho e as relações dos docentes com suas atividades cotidianas.

Do ponto de vista do capital, trata-se de aumentar o trabalho docente em extensão e intensidade. Segundo Bosi (2007, p. 1513),

[...] a pressão exercida para aumentar a quantidade de trabalho dentro da jornada de 40 horas tem se concretizado, principalmente, alicerçada na idéia de que os docentes devem ser "mais produtivos", correspondendo à "produção" a quantidade de "produtos" relacionados ao mercado (aulas, orientações, publicações, projetos, patentes etc.) expelidos pelo docente. Por um lado, evidencia esse processo o direcionamento empresarial da ciência, tecnologia, pesquisa, e desenvolvimento, presente nos editais dos órgãos de fomento à produção científica.

Aliada à demanda de quantidade de produção tem-se uma política avaliativa que valoriza a produtividade apresentada. Essa lógica do financiamento transforma o docente-pesquisador em um empreendedor e o leva a adequar a sua criação intelectual aos editais, a um determinado valor mensurado de uma forma determinada, restringindo os temas e metodologias a serem adotadas. Essas acomodações podem ser mais ou menos distantes das expectativas originais do pesquisador, mas certamente exigirão uma intensificação considerável do seu trabalho, particularmente na pós-graduação.

Silva Júnior et al. (2010) chamam a atenção para o modelo da Coordenação de Aperfeiçoamento de Pessoal de Nível Superior -Capes-, agência estatal, que além de financiar e induzir a organização dos programas de pós-graduação, também os avalia, criando um sistema de controle e regulação de cada um deles e do espaço social que eles compõem no Brasil. Segundo os autores, o modelo de avaliação da Capes modifica qualitativamente o trabalho do professor, que se mostra subordina- 
do aos seus meios e controles, ao concordar que é "sua responsabilidade" cumprir todas as exigências da agência estatal, ocasionando um alto nível de estresse.

É válido ressaltar, ainda, o fato de que a intensificação pode levar à persistência da cultura do individualismo entre os professores, ou seja, envolvidos nesse ambiente de intensa produtividade, competitividade e empreendedorismo torna-se difícil a produção coletiva de conhecimento. O processo de intensificação pode contribuir, devido à falta de tempo, para a diminuição, ou mesmo, a não participação do professor em espaços coletivos de reflexão e ação sobre a profissão docente, como sindicatos, associações, ou mesmo, grupos de estudos entre colegas de trabalho.

Cabe destacar também, que a maneira como o tempo de trabalho é empregado interfere, diretamente, no processo de desenvolvimento profissional do docente universitário, uma vez que, "a intensificação conduz a uma falta de tempo para o aperfeiçoamento das destrezas e para a actualização profissional” (HARGREAVES, 1998, p. 133). Esse processo gera como consequência "traduções simplificadas de saberes especializados impostos externamente" (Apple apud HARGREAVES, 1998, p. 134).

Nesse momento, faz-se necessário atentarmos também, para a precarização das condições de trabalho impostas aos professores universitários, a partir da reestruturação produtiva que impactou a forma de atuar no contexto educacional. O trabalho do professor, imaterial e superqualificado, adequado à reestruturação produtiva e tendo como paradigma a acumulação flexível, reforçou a produção científica pragmática e o aumento do trabalho imaterial e produtivo. Tudo isso modificou a identidade das IFES, as relações entre o Estado e as instituições, mas, sobretudo, o trabalho do professor. De acordo com Cislaghi (2011), nesse contexto o professor tornou-se um trabalhador polivalente, frente à flexibilização do seu processo de trabalho, visto que,

[...] a polivalência se expressa na demanda por múltiplas atividades: ensino, pesquisa- dentro do critério produtivista - extensão- sobretudo a partir da venda de serviços - e administração. Esse último aspecto tem sido cada vez mais exigido aos docentes que sofrem com a falta de recursos financeiros, de apoio administrativo e com a complexidade dos procedimentos e processos decisórios, tornando uma atividade que deveria ser acadêmica, em uma substituição de profissionais técnico-administrativos, também escassos nas instituições (LEMOS, 2010 apud CISLAGHI, 2011, p. 171).

Ancorando-se em dados do Inep, Silva Júnior et al. (2010) afirmam que o número de funcionários técnico-administrativos decresceu em mais de 30\% nas IFES entre 1995 e 2004. Os autores supõem que as novas tecnologias permitiram uma transferência de funções dessa categoria para os docentes, que passaram a preencher planilhas de notas, programas de disciplinas e formulários de agências de fomento. 
Essa precarização reflete-se na minimização de gastos aplicados na educação que, por sua vez, faz com que as condições de efetivação do trabalho docente sejam precárias em termos de salário, prestígio social, satisfação pessoal e profissional etc.

A partir da justificativa de minimização de gastos, o exercício do magistério superior vem sendo submetido a condições precárias, como a intensificação do ritmo do trabalho em paralelo ao achatamento e perdas salariais ${ }^{1}$, captura da subjetividade do trabalhador e retirada de direitos (FERRAZ, 2008).

Neste contexto, é válido ressaltar que ganham espaço dentro da universidade serviços de consultorias e desenvolvimento de produtos, o que constitui um tipo de mercantilização do trabalho docente. Nesse sentido, a prática dessas atividades pode levar, muitas vezes, a uma dependência dos docentes convertendo-os, muitas vezes, em captadores de recursos extra orçamentários.

Percebe-se então, que no atual cenário em que se encontra a universidade pública brasileira, as precárias condições de trabalho geradas pelas políticas educacionais contemporâneas, vêm se dando a um custo muito alto para o trabalhador docente. Os professores têm sofrido um aumento do seu ritmo de trabalho, bem como se tornam reféns da falta de tempo para preparar e refletir de forma crítica o seu trabalho.

Todos esses fatores interferem, consequentemente, no desenvolvimento profissional do docente universitário. Segundo Marcelo Garcia (2009, p. 7), a partir da última década tem se considerado o desenvolvimento profissional "como um processo a longo prazo, no qual se integram diferentes tipos de oportunidades e experiências, planificadas sistematicamente para promover o crescimento e o desenvolvimento do docente". O autor salienta que devemos entender o desenvolvimento profissional dos professores como a "construção do seu eu profissional que evolui ao longo da sua carreira docente e que pode ser influenciada pela escola, pelas reformas e contextos políticos" (idem, p. 11). Ele afirma ainda que, qualquer discussão sobre o processo de desenvolvimento profissional deve levar em consideração o significado do que é ser um profissional e qual o grau de autonomia desse profissional.

Sendo assim, é passível de entendimento que as condições de trabalho do professor universitário, geradas pelo contexto político atual, devem ser amplamente discutidas, uma vez que interferem diretamente no processo de desenvolvimento profissional docente.

\section{0 trabalho docente nas fontes pesquisadas}

Como já ressaltamos anteriormente, para a elaboração desse artigo sistematizamos estudos sobre as condições de trabalho docente na universidade pública brasileira, publicados no período de 2006-2010, em três fontes: Reuniões Anuais 
da ANPEd, Banco de Teses e Dissertações da CAPES e Revista Universidade e Sociedade. É esse esforço de sistematização e análise que vamos explicitar a seguir. Assim, na ANPEd foi realizado, junto ao site ${ }^{2}$ da Associação, um levantamento das reuniões anuais do período de 2006 à 2010. Foram selecionados 24 (vinte e quatro) trabalhos e pôsteres dos seguintes GTs: GT 08 (Formação de Professores); GT 09 (Trabalho e Educação) e GT 11 (Política de Educação Superior), que podem ser melhor visualizados no quadro a seguir:

Quadro 1: Distribuição de trabalhos e pôsteres por GT pesquisado - período de 2006 a 2010

\begin{tabular}{|l|c|c|c|c|}
\hline $\begin{array}{c}\text { Distribuição dos } \\
\text { trabalhos por ano }\end{array}$ & $\begin{array}{c}\text { GT 08 } \\
\text { Formação de Professores }\end{array}$ & $\begin{array}{c}\text { GT 09 } \\
\text { Trabalho e Educação }\end{array}$ & $\begin{array}{c}\text { GT 11 } \\
\text { Política de Educação } \\
\text { Superior }\end{array}$ & Total \\
\hline 2006 & 02 & 02 & 04 & 08 \\
2007 & 02 & 01 & 02 & 05 \\
2008 & 02 & - & 02 & 04 \\
2009 & 01 & 01 & 02 & 04 \\
2010 & 01 & 01 & 01 & 03 \\
Total $(\mathrm{n})$ & 08 & 05 & 11 & \\
\hline
\end{tabular}

Fonte: dados do site da ANPEd.

Após a leitura dos resumos foram localizados 7 (sete) artigos que se afinavam à temática em estudo. Os trabalhos que mais se aproximam da categoria trabalho docente encontram-se, em sua maioria, nos GT 09 (Trabalho e Educação), com três (03) trabalhos e no GT 11 (Política de Educação Superior) com quatro (04). No GT 08 (Formação de Professores) a ênfase maior foi dada aos processos constitutivos da formação docente no ensino superior. Nesse sentido, a discussão sobre trabalho docente constitui-se aí uma lacuna, o que pode ser visualizado no Quadro 2.

Quadro 2: Distribuição dos trabalhos e pôsteres nos GTs pesquisados, após leitura dos resumos - período de 2006 a 2010

\begin{tabular}{|l|c|c|c|c|}
\hline $\begin{array}{c}\text { Distribuição dos } \\
\text { trabalhos por ano }\end{array}$ & $\begin{array}{c}\text { GT 08 } \\
\text { Formação de Professores }\end{array}$ & $\begin{array}{c}\text { GT 09 } \\
\text { Trabalho e Educação }\end{array}$ & $\begin{array}{c}\text { GT 11 } \\
\text { Política de Educação } \\
\text { Superior }\end{array}$ & Total \\
\hline 2006 & - & 01 & - & \\
2007 & - & 01 & 01 \\
2008 & - & - & 01 \\
2009 & - & 01 & 01 & \\
2010 & - & - & 01 & \\
Total $(\mathrm{n})$ & - & 03 & 04 & 07 \\
\hline
\end{tabular}

Fonte: dados do site da ANPEd. 
Como se pode verificar, a discussão sobre trabalho docente é evidenciada em trabalhos que compõem o GT 09 - Trabalho e Educação, sendo recorrentes as discussões sobre a produtividade exigida dos professores/ pesquisadores da pós-graduação, após a política de avaliação implementada pela CAPES, conforme Quadro 3.

Quadro 3: Distribuição de trabalhos e pôsteres em relação ao GT 09 pesquisado no período de 2006 a 2010

\begin{tabular}{|c|l|l|}
\hline Ano & \multicolumn{1}{|c|}{ Títulos } & \multicolumn{1}{|c|}{ Autores } \\
\hline 2006 & $\begin{array}{l}\text { Trabalho docente e capitalismo: um estudo crítico da } \\
\text { produção acadêmica de 1990 } \\
\text { "Reféns da Produtividade": sobre produção do conhe- } \\
\text { cimento, saúde dos pesquisadores e intensificação } \\
\text { do trabalho na pós-graduação } \\
\text { Mutações do trabalho docente no ensino superior }\end{array}$ & $\begin{array}{l}\text { Klalter Bez Fontana; Paulo Sérgio Tumolo } \\
\text { (PPGE/ UFSC) }\end{array}$ \\
2009 & $\begin{array}{l}\text { Lucídio Bianchetti (UFSC); } \\
\text { Ana Maria Netto Machado (UNIPLAC) }\end{array}$ \\
\hline
\end{tabular}

Fonte: dados do site da ANPEd.

No GT11- Políticas para o Ensino Superior, são recorrentes, também, os trabalhos que analisam as regulações das políticas educacionais, buscando identificar as relações existentes entre a Reforma do Estado, as tendências da educação traduzidas pelas políticas e o estabelecimento de novas regulações no tocante à formação e ao trabalho docente.

Quadro 4: Distribuição de trabalhos e pôsteres em relação ao GT 11 pesquisado no período de 2006 a 2010

\begin{tabular}{|c|c|c|}
\hline Ano & Títulos & Autores \\
\hline 2007 & $\begin{array}{l}\text { Universidade Nova/ Plano de Reestruturação e Expansão das } \\
\text { Universidades Federais: mais uma dose da Reforma universitária? }\end{array}$ & $\begin{array}{l}\text { Denise Bessa Leda (UFMA/ } \\
\text { UERJ) }\end{array}$ \\
\hline 2008 & $\begin{array}{l}\text { A política de Educação Superior para a formação e o trabalho } \\
\text { docente: a nova regulação educacional. }\end{array}$ & $\begin{array}{l}\text { Olgaíses Cabral Maués } \\
\text { (UFPA) }\end{array}$ \\
\hline 2009 & $\begin{array}{l}\text { Na contracorrente: a política do governo Lula para a educação } \\
\text { superior. }\end{array}$ & $\begin{array}{l}\text { Éder Dantas (UFPB) } \\
\text { Luiz de Sousa Júnior (UFPB) }\end{array}$ \\
\hline 2010 & $\begin{array}{l}\text { A nova regulação educacional e o trabalho docente na pós-gradu- } \\
\text { ação brasileira. }\end{array}$ & $\begin{array}{l}\text { William Pessoa da Mota Júnior } \\
\text { (UFPA) } \\
\text { Olgaíses Cabral Maués (UFPA) }\end{array}$ \\
\hline
\end{tabular}

Fonte: dados do site da ANPEd.

No Banco de Teses da CAPES, ${ }^{3}$ foi realizado um levantamento de teses e dissertações no período de 2006 a 2010, por meio da busca das seguintes palavras-chave: Trabalho docente, condições de trabalho, ensino superior. Nessa primeira busca, foram encontrados onze trabalhos entre teses e dissertações. É válido ressaltar que outras buscas com palavras diferentes também foram realizadas, porém não superaram os resultados da primeira busca. 
Quadro 5: Distribuição de dissertações e teses no Banco da Capes, no período de 2006 a 2010

\begin{tabular}{|c|c|c|c|c|c|c|c|c|c|}
\hline \multicolumn{2}{|c|}{2006} & \multicolumn{2}{|c|}{2007} & \multicolumn{2}{|c|}{2008} & \multicolumn{2}{|c|}{2009} & \multicolumn{2}{|c|}{2010} \\
\hline$D$ & $\mathrm{~T}$ & D & $\mathrm{T}$ & $D$ & $\mathrm{~T}$ & $D$ & $\mathrm{~T}$ & $D$ & $\mathrm{~T}$ \\
\hline 01 & 01 & 01 & - & 01 & 01 & 02 & 01 & 01 & 02 \\
\hline
\end{tabular}

Fonte: dados do site da CAPES.

Após a leitura dos resumos foram selecionadas três dissertações e duas teses no período de 2006 a 2010, que apresentavam proximidade com o tema "trabalho docente" e "condições de trabalho".

Quadro 6: Distribuição de dissertações e teses no Banco da Capes, no período de 2006 a 2010

\begin{tabular}{|c|c|c|}
\hline Ano & Títulos & Autores \\
\hline 2007 & $\begin{array}{l}\text { Estresse laboral e docência: contribuição para a promoção da saú- } \\
\text { de no ambiente universitário. (Dissertação de Mestrado) }\end{array}$ & $\begin{array}{l}\text { FROTA, Áurea Maria Car- } \\
\text { minha da, (Unifor). }\end{array}$ \\
\hline \multirow[t]{2}{*}{2008} & $\begin{array}{l}\text { O ensino superior e a reestruturação produtiva no mundo do traba- } \\
\text { Iho: o impacto da precarização nas relações de trabalho dos docen- } \\
\text { tes no ensino superior de Uberlândia (Dissertação de Mestrado) }\end{array}$ & $\begin{array}{l}\text { FRANÇA, Polyana Imolesi } \\
\text { Silveira de, (UFU). }\end{array}$ \\
\hline & $\begin{array}{l}\text { Reconfiguração das Universidades Estaduais do Paraná - um estu- } \\
\text { do das mudanças no trabalho docente. (Tese de Doutorado) }\end{array}$ & $\begin{array}{l}\text { PADILHA, Regina Célia } \\
\text { Habib Wipieski, (UNIMEP). }\end{array}$ \\
\hline \multirow[t]{2}{*}{2009} & $\begin{array}{l}\text { Docência e Universidade Pública: um estudo das relações de } \\
\text { trabalho vivenciadas pelo professor substituto da Faculdade de } \\
\text { Educação da Universidade Federal do Amazonas. (Dissertação de } \\
\text { Mestrado) }\end{array}$ & $\begin{array}{l}\text { POSSATO, Luciana. } \\
\text { (UFU), (UFAM). }\end{array}$ \\
\hline & $\begin{array}{l}\text { A metamorfose do trabalho docente no ensino superior: entre o } \\
\text { público e o mercantil. (Tese de Doutorado) }\end{array}$ & $\begin{array}{l}\text { SILVA, Maria Emília Perei- } \\
\text { ra da, (UERJ). }\end{array}$ \\
\hline
\end{tabular}

Fonte: dados do site da ANPEd.

Esses estudos tratam das condições de trabalho docente, sobretudo a partir da reestruturação produtiva do mundo do trabalho e dos contextos das relações sociais de produção sob a égide do capital financeiro, suas implicações no campo produtivo e desdobramentos das políticas neoliberais no país. Tais fatores afetam a universidade pública e consequentemente o trabalho docente que vem sendo precarizado e intensificado, categorias presentes nesses trabalhos.

A discussão sobre condições de trabalho docente aparece nos anos de 2007, 2008 e 2009, mas não a encontramos nos anos de 2006 e 2010. Mesmo assim, é passível de entendimento, que o número de trabalhos que discutem essa temática ainda é incipiente, uma vez que totalizam cinco trabalhos em um período de cinco anos. Contudo, é válido ressaltar a possibilidade de existência de mais trabalhos sobre esse tema, que podem não ter sido contemplados pela busca com as palavras-chave, trabalho docente, condições de trabalho e ensino superior. 
Na Revista Universidade e Sociedade ${ }^{4}$, no período de 2006 a 2011, foi realizado um levantamento dos artigos publicados e, inspirando-se na análise de conteúdo (FRANCO, 2005), foram elaboradas três categorias (grandes temas), para análise dos artigos, que se relacionam às condições de trabalho na universidade pública, sendo elas: Universidade em que são contemplados artigos que abordam a universidade no contexto atual; Trabalho Docente em que são agregados artigos que abordam diretamente o trabalho docente na universidade e as condições em que esse trabalho ocorre; e Políticas para o Ensino Superior em que são abordados artigos que tratam das principais políticas para o ensino superior, principalmente no Governo Lula da Silva.

Entende-se que essas categorias de análise se relacionam e fornecem elementos para se pensar as condições de trabalho do docente universitário. Tais condições, não podem ser analisadas sem levar em conta o contexto atual da universidade pública brasileira e as políticas públicas que regem o ensino superior.

Primeiramente a seleção dos artigos foi feita a partir da leitura dos títulos nos sumários das revistas. Em seguida, procedeu-se a uma análise mais aprofundada dos títulos e resumos dos artigos, buscando uma aproximação com a temática "trabalho docente". Foram analisados 47 (quarenta e sete artigos) - dentro das três categorias analíticas - sendo que 16 (dezesseis) deles se inseriam diretamente na categoria "trabalho docente", como se pode ver na tabela 1.

Tabela 1: Distribuição dos artigos analisados da Revista Universidade e Sociedade por categorias

\begin{tabular}{l|c|c}
\hline Categorias & Número de artigos & Percentual (\%) \\
\hline Universidade & 17 & $36,1 \%$ \\
Trabalho docente & 16 & $34,0 \%$ \\
Políticas para o ensino superior & 14 & $29,7 \%$ \\
Total & 47 & $100 \%$ \\
\hline
\end{tabular}

Fonte: dados construídos a partir da consulta a revista Universidade e Sociedade.

Dessa forma, podemos inferir que, no levantamento realizado na Revista Universidade e Sociedade, a temática "trabalho docente" e "condições de trabalho" na universidade pública, são significativamente contempladas. Diante das três categorias universidade, trabalho docente e políticas para o ensino superior, elaboradas para análise dos 47 artigos, encontramos 34,0\% de artigos diretamente relacionados à abordagem do trabalho docente na universidade pública. Existe a recorrência de categorias concernentes ao trabalho docente como precarização, intensificação, superexploração e alienação. Nesse contexto, percebe-se que os artigos abordam a temática "trabalho docente" relacionando-o ao produtivismo acadêmico, à expansão do número de alunos na graduação, à organização do trabalho na gra- 
duação e na pós-graduação. Percebe-se uma lacuna em relação à injunção dessas categorias ao fator salarial, que é contemplado apenas em um artigo relacionado à superexploração do trabalho docente.

\section{Considerações finais}

O levantamento dos estudos nos permitiu perceber que as pesquisas sobre os temas "trabalho docente" e "condições de trabalho" na universidade pública brasileira, tem aparecido de formas distintas nas fontes pesquisadas. Assim, o tema aparece de forma incipiente nas Reuniões Anuais da ANPEd e no Banco de Teses e Dissertações da Capes. Já na Revista Universidade e Sociedade, o tema é significativamente contemplado. Isso pode ocorrer em virtude de a revista tratar mais especificamente do ensino superior e ser publicada pelo Sindicato Nacional dos Docentes das Instituições de Ensino Superior (ANDES - SN).

E válido ressaltar a importância desse estudo do tipo estado da arte, uma vez que possibilitou verificar como e quanto o trabalho docente e as condições em que esse trabalho ocorre estão sendo discutidas no âmbito da produção acadêmica. Reitera-se que o trabalho docente não pode ser discutido fora do contexto macrossocial em que se encontra a universidade e, por sua vez, a sociedade. A universidade reorganiza-se constantemente frene às demandas da sociedade, e os professores, consequentemente, têm o seu trabalho alterado diante dessa dinâmica.

Por fim, entende-se que os estudos sobre as condições de trabalho docente na universidade pública ainda constituem uma lacuna. Precisam ser intensificados, sobretudo, nesse contexto de expansão trazido pelo Reuni que tem aprofundado uma lógica gerencial de gestão com financiamento por contrato baseado em resultados e metas. Esse princípio compromete o conceito de autonomia universitária, pois trata-se muito mais de uma autonomia administrativa, com liberdade para captação de recursos orçamentários, do que uma autonomia didático-pedagógica.

\section{Working conditions of professors in brazilian public university: a study mapping}

\section{Abstract}

This work analyzes studies on working conditions of professors in Brazilian public universities, published between 2006 and 2010, achieved from three sources: Annual Meetings of ANPEd, CAPES Collection of Theses and Dissertations and the journal Revista Universidade e Sociedade. We sought to map and analyze publications from these sources. At first, the work presented a literature review on teaching in Brazilian public universities. Then, a survey was carried out on works on that the- 
me found in the three sources mentioned. It should be highlighted that this theme is still scarcely addressed at the ANPEd annual meetings and in the CAPES Collection of Theses and Dissertations. On the other hand, it is significantly addressed in the journal Revista Universidade e Sociedade, probably because it focuses on discussions on higher education issues. This review demonstrates that studies on working conditions of professors in public universities are few and should receive more attention, especially due to the present expansion of public institutions of higher education resulting from the REUNI program.

Keywords: Teaching work; working conditions; public university

\section{Notas}

1 Segundo Silva Júnior et al (2010, p. 21), o salário do professor titular doutor, em regime de dedicação exclusiva, das universidades federais se reduziu, com correção inflacionária, de R $\$ 10.092 .96$ em 1995, para $\mathrm{R} \$ 7.830 .13$ em 2007, um decréscimo de aproximadamente $25 \%$.

$2 \mathrm{O}$ acesso ao site da ANPEd pode se dar pelo endereço eletrônico da associação: www.anped.org.br.

$3 \mathrm{O}$ acesso à CAPES se deu pelo seguinte endereço eletrônico: http://www.capes.gov.br/servicos/banco-de-teses.

4 A publicação da revista é semestral, correspondendo, assim, a duas edições por ano. A referida revista é publicada pelo Sindicato Nacional dos Docentes das Instituições de Ensino Superior (ANDES - SN).

\section{Referências}

ASSOCIAÇÃO dos docentes da Universidade de Brasília. Decretos apontam para expansão precária das universidades e sobrecarregam o sistema. Campanha Salarial. Edição Especial. Brasília, ago. 2007. Disponível em: <http://www.andes.org.br/bol_especial_adunb_agosto07.pdf >. Acesso em: 20 set. 2010.

BOSI. A. P. A precarização do trabalho docente nas instituições de ensino superior do Brasil nesses últimos 25 anos. Educ. Soc. [on-line]. 2007, vol.28, n.101, pp. 1503-1523. Disponível em: <http://www.scielo.br/scielo.php?pid=S0101-73302007000400012\&script=sci_abstract\&tlng=e > Acesso em: 20 fev. 2010.

BRASIL. REUNI - Reestruturação e Expansão das Universidades Federais: Diretrizes Gerais, Brasília, 2007.

Decreto no 6.096 de 24 de abril de 2007. Institui o Programa de Apoio a Planos de Reestruturação e Expansão das Universidades Federais - REUNI. Brasília, 25 de abril de 2007. Disponível em: <http://www.planalto.gov.br//CCIVIL/_Ato2007-2010/2007/Decreto/D6096.htm>. Acesso em: 27 de ago. 2010.

CISLAGHI, J. F. Precarização e superexploração do trabalho docente: a expansão das matrículas e o aumento da relação professor/aluno. Universidade e Sociedade, Brasília, DF, ano XX, no 47, fevereiro de 2011. Semestral.

FERRAZ, C. L. Trabalho docente, precarização e a nova hegemonia do capital. Universidade e Sociedade, n. 41, p. 9-19, jan. 2008.

FRANCO, M. L. P. B. Análise de conteúdo. 1. ed. Brasília: Líber Livro, 2005. 
HARGREAVES, A. A intensificação: o trabalho dos professores- melhor ou pior. In: HARGREAVES, A. Os professores em tempo de mudança. O trabalho e a cultura dos professores na Idade Pós-Moderna. Alfragide - Portugal: McGraw-Hill de Portugal, 1998. p. 131-158.

MAUÉS, O. O produtivismo acadêmico e o trabalho docente. Universidade e Sociedade, Brasília, DF, n. 41, jan. 2008, p. 21-31.

MARCELO, Carlos. Desenvolvimento Profissional Docente: passado e futuro. Sísifo, Revista de Ciências da Educação, Lisboa Portugal, n. 8, p. 7-22, jan/abr. 2009.

OLIVEIRA, D. A. A reestruturação do trabalho docente: precarização e flexibilização. Educação e Sociedade, Campinas, v. 25, n. 89, p. 1127-1144, set./dez. 2004.

OLIVEIRA, D. A; GONÇALVES, G. B.; MELO, S. D.; FARDIN, V.; MILL, D. Transformações na Organização do Processo de Trabalho Docente e o suas consequências para os professores. Trabalho e Educação, Belo Horizonte, n. 11, p. 37-54. jul.dez./2002.

ROMANOWSKI, J. P.; ENS, R. T. As pesquisas denominadas do tipo "estado da arte" em educação. Revista Diálogo Educacional [on-line]. 2006, v. 6, n. 19, pp. 37-50. Disponível em: <http:// redalyc.uaemex.mx/redalyc/pdf/1891/189116275004.pdf>. Acesso em: 5 nov. 2013.

SANTOS, L. L. C. P. Formação de professores na cultura do desempenho. Educação e Sociedade, Campinas, v. 25, n. 89, p. 1145-1157, set./dez. 2004.

SILVA JÚNIOR J. dos R.; SGUISSARDI, V.; SILVA, E. P. e. Trabalho intensificado na universidade pública brasileira. Universidade e Sociedade, Brasília, DF, n. 45, ano XIX, p. 9-25, jan. 2010. Semestral. 